\title{
Indirect Red and Near-Infrared Z-to-E Photoisomerization of ortho- Functionalized Azobenzenes via Triplet Energy Transfer
}

\author{
Jussi Isokuortti, Kim Kuntze, Matti Virkki, Zafar Ahmed, Elina Vuorimaa-Laukkanen, Mikhail A. \\ Filatov, Andrey Turshatov, Timo Laaksonen, Arri Priimagi, and Nikita A. Durandin*
}

\begin{abstract}
Designing azobenzene photoswitches capable of selective and efficient photoisomerization by long wavelength excitation is a long-standing challenge. Indirect excitation can expand the properties of the photoswitching system beyond the intrinsic limits of azobenzenes. Herein, a rapid $Z$-to- $E$ isomerization of two ortho-functionalized azobenzenes with nearunity photoconversion was facilitated via triplet energy transfer upon red and near-infrared (up to $770 \mathrm{~nm}$ ) excitation of porphyrin photosensitizers in catalytic micromolar concentrations. Our results indicate that the whole process of tripletsensitized isomerization is strongly entropy-driven. This ensures efficient $Z$-to- $E$ photoswitching even when the azobenzene triplet energy is considerably higher $(>200 \mathrm{meV})$ than for the sensitizer, which is the key for the expansion of excitation wavelengths into the near-infrared spectral range.
\end{abstract}

Azobenzenes are widely utilized as photoswitches to enable light as a versatile and efficient stimulus for functional materials. ${ }^{1,2}$ The spatiotemporal precision and non-invasiveness of light are especially desired to control biological functions.3,4 Developing azobenzenes with suitable properties, such as excitation wavelengths or lifetime of the metastable cis-isomer, typically requires structural modification; ${ }^{5}$ a complex approach that generally involves extensive computational studies and synthesis. For example, ortho-functionalization of azobenzenes is an established approach to create photoswitches with extremely long cis-lifetime, ${ }^{6-8}$ which are the key to systems with effective photoswitching in both directions and precise control of the isomer composition. In addition to thermal relaxation or direct excitation of the azobenzene, isomerization can be effected in various indirect ways, such as photoinduced electron transfer ${ }^{9-11}$, photon upconversion $^{12,13}$ and triplet sensitization ${ }^{10,14-17}$. Thus, indirect excitation allows tailoring and expansion of the photoswitching properties of the system beyond the capabilities of the azobenzene itself.

Triplet-sensitized $Z$-to- $E$ isomerization of azobenzenes is especially viable due to its reversibility, non-destructivity and near-unity conversion into the $E$-isomer.14,17,18 In previous reports the triplet sensitizers have been excited in UV-to-yellow ( $<580 \mathrm{~nm}$ ) range. However, the capabilities of potent red and NIR-absorbing triplet sensitizers, such as porphyrins, have not been utilized in azobenzene photoswitching. Thus, we set out to study this approach and explore the limits of the triplet-sensitized photoisomerization wavelengths. Due to the optical properties of tissue, photoswitching systems capable of operating under red or even near-infrared (NIR) light are of particular interest for biomedical applications. ${ }^{4,19-22}$
Here we demonstrate triplet-sensitized Z-to- $E$ isomerization of azobenzenes under red and NIR excitation and establish its efficiency with detailed kinetic studies. We have employed a NIR-absorbing porphyrin, PdNP (Pd(II) meso-tetraphenyltetranaphthoporhyrin ${ }^{23-25}$ ) and two commercially available red-absorbing porphyrins, PdP and PtP (Pd(II) and Pt(II) mesotetraphenyltetrabenzoporphyrin, see Chart 1), as triplet photosensitizers. The sensitizers were paired with tetrafluoroazobenzene $\quad\left(\mathrm{TFA}^{6,26}\right)$ and fluoropyrrolidineazobenzene (FPA ${ }^{27}$, see Chart 1). Both of these ortho-functionalized azobenzenes exhibit efficient photoisomerization ( $>80 \%$ conversion to both $Z$ - and $E$ isomers) under visible light ex citation and remarkably long thermal half-lives (days). TFA requires blue-light (410 $\mathrm{nm})$ for Z-to- $E$ photoisomerization. Contrarily, Z-FPA absorbs, although weakly, red light and thus it was used to compare photoisomerization under direct and triplet-sensitized excitation. 
Chart 1. Sensitizers and azobenzenes used in this study.

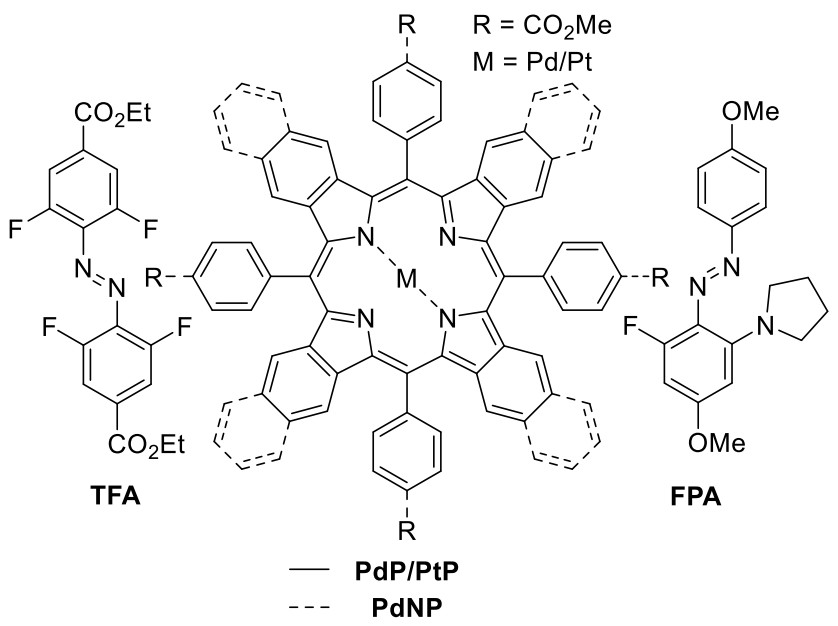

All experiments were conducted in DMSO. Since triplet sensitizers generate reactive oxygen species under illumination, bis(methylthio)methane was added as an oxygen scavenger. ${ }^{28}$ To study the triplet energy transfer (TET) from PdP and PtP to the azobenzenes, we performed quenching studies by measuring the phosphorescence lifetimes of both sensitizers in the presence of $E$ - or $Z$ isomers of both azobenzenes. The resulting Stern-Volmer plots of the quenching studies are shown in Fig. 1. The Stern-Volmer rate constant $\left(\mathrm{K}_{\mathrm{SV}}\right)$ yielded by the linear fit on the quenching data was then used to evaluate the rate constant of triplet energy transfer:

$$
\mathrm{k}_{\mathrm{TET}}=\frac{\mathrm{K}_{\mathrm{SV}}}{\tau_{0}}
$$

where $\tau_{0}$ is the unquenched phosphorescence lifetime of the sensitizer $(260 \mu$ s and $46 \mu$ s for PdP and PtP, respectively). The quenching experiments are discussed in more detail in the Supporting Information.
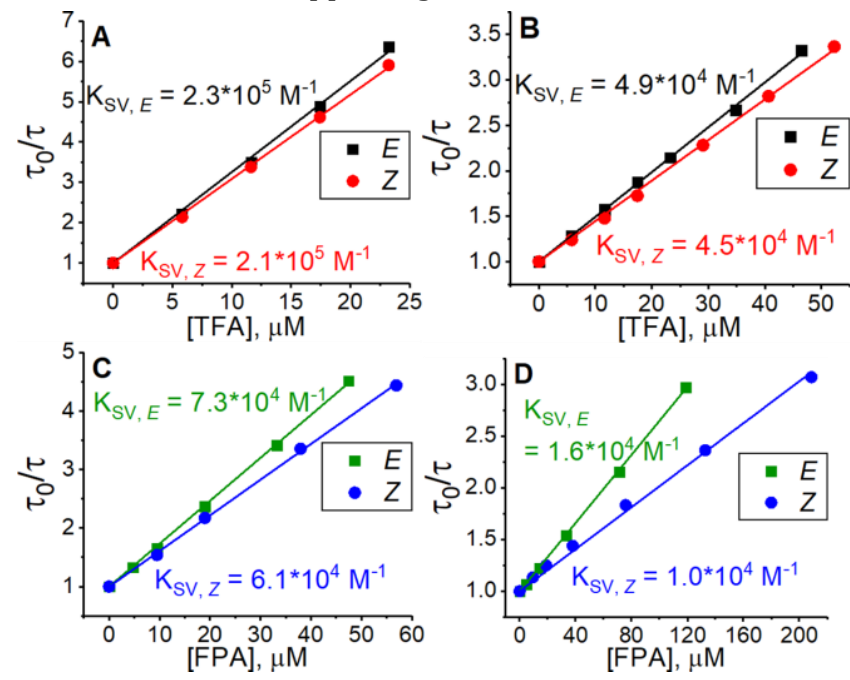

Figure 1. Results of the phosphorescence quenching. SternVolmer plots and the corresponding $K_{S V}$ values of (A) TFA and PdP, (B) TFA and PtP, (C) FPA and PdP and (D) FPA and PtP. $\mathrm{k}_{\text {TET }}$ values were then used to calculate the triplet energy gap $\left(\Delta \mathrm{E}_{\mathrm{T}}\right)$ between the sensitizer and azobenzene triplet states: ${ }^{29}$

$$
\frac{\Delta \mathrm{E}_{\mathrm{T}}}{\mathrm{k}_{\mathrm{B}} \mathrm{T}}=\ln \left(\frac{\mathrm{k}_{\mathrm{diff}}}{\mathrm{k}_{\mathrm{TET}}}-1\right),
$$

where $\mathrm{k}_{\mathrm{B}}$ is the Boltzmann constant, $\mathrm{T}$ is the temperature and $\mathrm{k}_{\text {diff }}\left(=1.1 \times 10^{9} \mathrm{M}^{-1} \mathrm{~S}^{-1}\right)$ is the diffusion rate constant of the system (see SI). Finally, the obtained $\Delta \mathrm{E}_{\mathrm{T}}$ values were used together with the sensitizer triplet energies (1.55 and $1.61 \mathrm{eV}$ for PdP and PtP, respectively, see Fig. S3) to evaluate the triplet energies $\left(\mathrm{E}_{\mathrm{T}}\right)$ of the azobenzenes in both $E$ - and $Z$-isomers. To our knowledge, these are the first reported triplet state energies of ortho-substituted azobenzenes. The $\mathrm{k}_{\mathrm{TET}}, \Delta \mathrm{E}_{\mathrm{T}}$ and $\mathrm{E}_{\mathrm{T}}$ values of each pair are shown in Table 1.

Table 1. Rate constant of triplet energy transfer ( $\left.k_{T E T}\right)$, triplet energy gap $\left(\Delta \mathrm{E}_{\mathrm{T}}\right)$ between sensitizer and azobenzene, and the triplet energy $\left(E_{T}\right)$ of the azobenzene de-

\begin{tabular}{|c|c|c|c|c|}
\hline Pair & $\begin{array}{c}\mathrm{k}_{\text {TET }} \\
\left(\mathrm{M}^{-1} \mathrm{~S}^{-1}\right)\end{array}$ & $\begin{array}{c}\Delta \mathrm{E}_{\mathrm{T}} \\
\left(\mathrm{k}_{\mathrm{B}} \mathrm{T}\right)\end{array}$ & $\begin{array}{c}\Delta \mathrm{E}_{\mathrm{T}} \\
(\mathrm{meV})\end{array}$ & $\begin{array}{c}\mathrm{E}_{\mathrm{T}} \\
(\mathrm{eV})\end{array}$ \\
\hline$E$-TFA/ PdP & $8.7 \times 10^{8}$ & -1.3 & -34 & \multirow{2}{*}{$\begin{array}{c}1.49- \\
1.52\end{array}$} \\
\hline$E$-TFA/ PtP & $1.1 \times 10^{9}$ & -4.7 & -120 & \\
\hline Z-TFA/ PdP & $8.1 \times 10^{8}$ & -1.0 & -26 & \multirow{2}{*}{$\begin{array}{c}1.52- \\
1.56\end{array}$} \\
\hline Z-TFA/ PtP & $9.7 \times 10^{8}$ & -2.0 & -52 & \\
\hline$E$-FPA/ PdP & $2.8 \times 10^{8}$ & 1.1 & 29 & \multirow{2}{*}{$\begin{array}{c}1.58- \\
1.63\end{array}$} \\
\hline$E$-FPA/ PtP & $3.6 \times 10^{8}$ & 0.7 & 18 & \\
\hline$Z$-FPA/ PdP & $2.4 \times 10^{8}$ & 1.3 & 34 & \multirow{2}{*}{$\begin{array}{c}1.58- \\
1.65\end{array}$} \\
\hline Z-FPA/ PtP & $2.2 \times 10^{8}$ & 1.4 & 36 & \\
\hline
\end{tabular}
rived from the quenching results.

Interestingly, the $Z$-isomers of TFA and FPA have higher $\mathrm{E}_{\mathrm{T}}$ than the $E$-isomer, which appears contrary to the unsubstituted azobenzene ( $\mathrm{E}_{\mathrm{T}}$ of $Z$-isomer $29 \mathrm{kcal} / \mathrm{mol}$ i.e. $1.29 \mathrm{eV}$ ), whereas the $\mathrm{E}_{\mathrm{T}}$ values of $E$-TFA and $E$-FPA are comparable to the previously reported values for unsubstituted and para-substituted azobenzenes (33-35 $\mathrm{kcal} / \mathrm{mol}$ i.e. 1.43-1.52 eV). The kinetic results also reveal the thermodynamics between the sensitizer and azobenzene: triplet energy transfer from both PdP and PtP appears exothermic to TFA (negative $\Delta \mathrm{E}_{\mathrm{T}}$ ), while the lower values of $\mathrm{k}_{\text {TET }}$ between the sensitizers and FPA indicate endothermic energy transfer (positive $\Delta \mathrm{E}_{\mathrm{T}}$ ).

Equipped with these findings, we employed both PdP and PtP for photoswitching of TFA and FPA, in order to study the effect of the triplet energetics on the photoisomerization. In agreement with previous works ${ }^{14,16,17}, E$-to- $Z$ isomerization was negligible when exciting the sensitizer. This was observed although TET is more affordable to the $E$-isomer than to the $Z$-isomer for both TFA and FPA (vide infra). However, after isomerizing the azobenzenes to their $Z$ configuration by directly exciting the $E$-isomer $(525 \mathrm{~nm}$ for TFA and $405 \mathrm{~nm}$ for FPA), rapid and nearly complete $Z$-to- $E$ isomerization could be readily induced under $640 \mathrm{~nm}$ excitation using catalytic amounts $(1.8 \mu \mathrm{M}$ i.e. $1.2 \mathrm{~mol} \%$ of the azobenzene) of each sensitizer (see Fig. 2). An exponential function was fitted to the isomerization data to 
extract the rates of isomerization $\left(\mathrm{r}_{Z \rightarrow E}\right)$. The resulting fits are shown in Fig. S12-S16. The rates of the $Z$-to- $E$ isomerization are clearly increased by orders of magnitude by using indirect excitation via the triplet energy transfer route. For example, the photoisomerization rate of FPA by triplet sensitization was over 100 times faster than under $640 \mathrm{~nm}$ direct excitation (3.10 $\mathrm{min}^{-1}$ versus $0.028 \mathrm{~min}^{-1}$ ). As expected, no isomerization of TFA without sensitizers was observed under $640 \mathrm{~nm}$ excitation. Notably, the sensitized photoswitching of FPA, to which TET is endothermic and thus slower, appears as rapid as photoswitching of TFA.
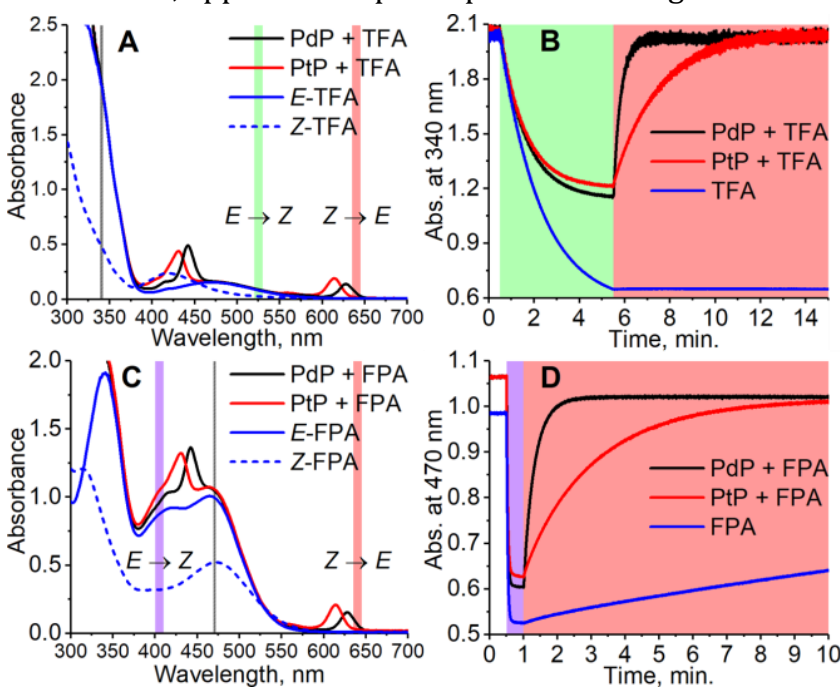

Figure 2. The absorption spectra of the photoswitching systems consisting of PdP and PtP and TFA (A) and FPA (C) and their photoisomerization curves (B) and (D). The colored sections indicate the wavelength and time ranges used for photoswitching. Excitation light is on during the times indicated by the representative colors. Gray lines in (A) and (C) indicate the wavelength used for monitoring the isomerization. The observed partial $E$-to- $Z$ isomerization of the azobenzenes, especially in case of TFA due to its small molar extinction coefficient at $525 \mathrm{~nm}$, is caused by competing absorption between the azobenzene and the sensitizer.

The conversion efficiency of the sensitized $Z$-to- $E$ isomerization $\left(\Phi_{Z \rightarrow E}\right)$ was determined from the curves as the ratio of initial (dark) and final (achieved upon sensitization) absorbances. All values were close to unity, and only a minor difference on the conversion efficiency was observed between TFA and FPA. $\mathrm{r}_{Z \rightarrow E}$ and $\Phi_{Z \rightarrow E}$ values of each sensitizer/azobenzene pair are shown in Table 2.
Table 2. Rates $\left(\mathrm{r}_{Z \rightarrow E}\right)$ and efficiency $\left(\Phi_{Z \rightarrow E}\right)$ of the photoisomerization under $640 \mathrm{~nm}$ excitation.

\begin{tabular}{|c|c|c|c|c|}
\hline Pair & $\begin{array}{c}\text { TFA/ } \\
\text { PdP }\end{array}$ & $\begin{array}{c}\text { TFA/ } \\
\text { PtP }\end{array}$ & $\begin{array}{c}\text { FPA/ } \\
\text { PdP }\end{array}$ & $\begin{array}{c}\text { FPA/ } \\
\text { PtP }\end{array}$ \\
\hline $\begin{array}{c}\mathrm{r}_{Z \rightarrow E} \\
\left(\mathrm{~min}^{-1}\right)\end{array}$ & 3.10 & $0.50^{\mathrm{a}}$ & 3.10 & $0.49 \mathrm{a}$ \\
\hline $\begin{array}{c}\Phi_{Z \rightarrow E} \\
(\%)\end{array}$ & 99 & 99 & 96 & 96 \\
\hline
\end{tabular}

a The smaller $\Phi_{Z \rightarrow E}$ yielded by PtP results mainly from smaller spectral overlap between its absorption and the excitation (see Fig. 2).

Surprisingly, the sensitizers appear to catalyze the Z-to- $E$ isomerization of FPA also in the dark (see Fig. S18). This increase in the rate of the thermal isomerization is especially pronounced with PtP as the contribution of the dark reaction to the overall observed rate is $31 \%(0.15 \mathrm{~min}-$ 1). In case of FPA/PdP, the contribution is only ca. $2 \%(0.06$ $\left.\mathrm{min}^{-1}\right)$. Also, the free base of the porphyrin $\left(\mathrm{H}_{2} \mathrm{P}\right)$ catalyzes the isomerization of FPA in the dark $\left(0.09 \mathrm{~min}^{-1}\right)$. This catalytic effect is perhaps a result of ground state coordination $^{30,31}$ between $Z$-FPA and the porphyrin. FPA has three $\pi$ donors in ortho- and para-positions and only one electron-withdrawing fluorine substituent, increasing the affinity of the azo bridge to an electron-deficient site such as a metal cation. The effect is not observed with the drastically electron-poorer TFA, which supports this explanation.

To better understand the observed results of tripletsensitized photoswitching and the considerably increased isomerization rates, we conducted an analysis of the underlying reaction mechanisms that can be described with the following set of equations: ${ }^{14,17}$

$$
\begin{aligned}
& { }^{3} \mathrm{~S}^{*}+E \text {-Azo } \stackrel{\mathrm{k}_{\mathrm{TET}-E}}{\longrightarrow} \mathrm{S}+{ }^{3} \mathrm{Azo}^{*} \\
& { }^{3} \mathrm{~S}^{*}+Z \text {-Azo } \stackrel{\mathrm{k}_{\mathrm{TET}-Z}}{\longrightarrow} \mathrm{S}+{ }^{3} \mathrm{Azo}^{*} \\
& { }^{3} \mathrm{Azo}^{*} \stackrel{\mathrm{k}_{\text {ISC-E }}}{\longrightarrow} E \text {-Azo } \\
& { }^{3} \mathrm{Azo} \stackrel{\mathrm{k}_{\mathrm{ISC}-}}{\longrightarrow} Z \text {-Azo }
\end{aligned}
$$

where $S$ is the sensitizer, superscript 3 is the triplet state, ISC is intersystem crossing between singlet and triplet state and $\mathrm{k}$ denotes the rate constant of each process. $\mathrm{k}_{\mathrm{TET}-E}$ and $\mathrm{k}_{\mathrm{TET}-Z}$ are determined experimentally and given in Table 1. It is also important to notice, that ${ }^{3} \mathrm{Azo}^{*}$ can be considered as a common state between the isomers, since there is no energy barrier associated with the CNNC twist in the triplet manifold. ${ }^{18,32}$ While there are no direct observations reported on the triplet lifetime of azobenzenes, the commendable computational work ${ }^{18}$ by Cembran et al. estimates $\mathrm{k}_{\mathrm{ISC}-E}$ as $10^{11} \mathrm{~s}^{-1}$. The ultrafast ISC results from the degeneracy between the minimum of the triplet state and the intersection between triplet state and ground state of $E$ Azo. Since the photostationary composition yielded by sensitized isomerization can be derived from the equations above as ${ }^{14,17}$

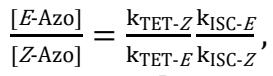

we can use $\Phi_{Z \rightarrow E}$ and the TET results to estimate relative 
$\mathrm{k}_{\mathrm{ISC}-Z}$ for TFA $\left(10^{9} \mathrm{~s}^{-1}\right)$ and FPA $\left(3 \times 10^{9} \mathrm{~s}^{-1}\right)$, corresponding roughly to $1-3 \%$ of $\mathrm{k}_{\mathrm{ISC}-E}$. This also explains why triplet sensitization of azobenzene leads almost exclusively to $E$ isomer. ${ }^{14,17,18}$

Based on the isomerization kinetics, even endothermic TET (as is the case with FPA) is apparently capable of driving isomerization efficiently. This indicates that the whole process of triplet-sensitized isomerization is largely entropy-driven ${ }^{33,34}$, since the rate of the isomerization is fairly decoupled from the change in enthalpy involved in TET. The change in entropy $(\Delta S)$ of TET is ${ }^{33}$

$$
\Delta \mathrm{S}=\mathrm{k}_{\mathrm{B}} \ln \left(\frac{[\mathrm{Z}-\mathrm{Azo}]\left[{ }^{3} \mathrm{~S}^{*}\right]}{[\mathrm{S}]\left[{ }^{3} \mathrm{Azo}^{*}\right]}\right) \text {. }
$$

The ultrafast crossing between the triplet state and the ground state of $E$-Azo (Eq. 5) leads to $\left[{ }^{3} \mathrm{Azo}^{*}\right] \ll[Z$-Azo], $\left[{ }^{3} \mathrm{~S}^{*}\right],[\mathrm{S}]$ and ensures a large entropy component in the triplet-sensitized isomerization. This also effectively eliminates the azobenzene-to-sensitizer reverse TET. ${ }^{34}$ Therefore, even photosensitizers with considerably lower triplet energies are still capable of sensitizing the $Z$-to- $E$ isomerization of azobenzenes, which enables the expansion of excitation wavelengths to deeper red and even into NIR.

Prompted by this finding, we paired TFA with PdNP, a sensitizer with triplet energy of $1.30 \mathrm{eV}$ and strong absorption in the NIR (see Fig. S2 and S4). The triplet energy gap of this pair is thus $\geq 220 \mathrm{meV}$, i.e., $8.5 \mathrm{k}_{\mathrm{B}} \mathrm{T}$ and as a result, TET is highly endothermic. Nonetheless, photoisomerization under $740 \mathrm{~nm}$ excitation was, to our delight, efficient despite this remarkably high endothermic energy gap (see Fig. 3). PdNP was capable of sensitizing isomerization of TFA even under $770 \mathrm{~nm}$ excitation $\left(\mathrm{r}_{Z \rightarrow E}=\right.$ $0.93 \mathrm{~min}^{-1}$, see Fig. S14).
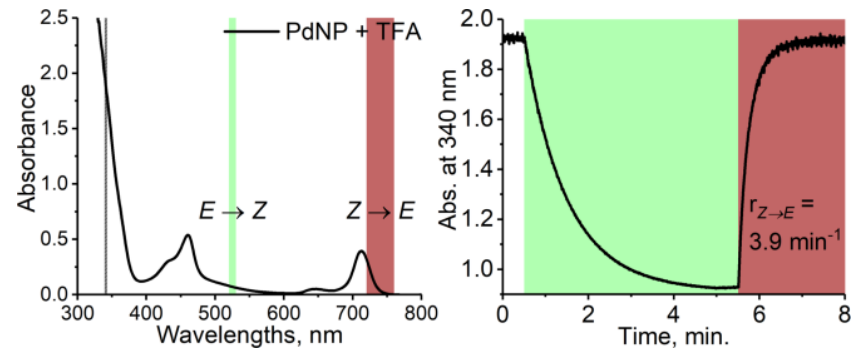

Figure 3. Absorption spectrum of PdNP and TFA (left) and the photoisomerization curve (right) under $525 \mathrm{~nm}$ (green color) and $740 \mathrm{~nm}$ (dark red) excitation with the resulting rate of isomerization.

Thanks to the bistable nature and rapid triplet-sensitized isomerization of TFA under NIR excitation, the isomer composition can be precisely controlled by modulating the excitation dose (duration and/or intensity). This stepwise photoisomerization by dosed excitation is shown in Fig. 4. Repeatable cyclic switching between isomers is also typically desired for applications of photoswitching. This can be achieved in triplet-sensitized photoswitching systems by alternating excitation of azobenzene and sensitizer as shown in Fig. 4 No discernible change in the rate of the sensitized isomerization and only slight decrease in efficiency (less than $10 \%$, likely due to photobleaching) was observed in 10 cycles. Photoswitching is achievable even in presence of oxygen (Fig. S19), when the effects of singlet oxygen generated by the photosensitizer are mitigated by employing oxygen-scavengers.
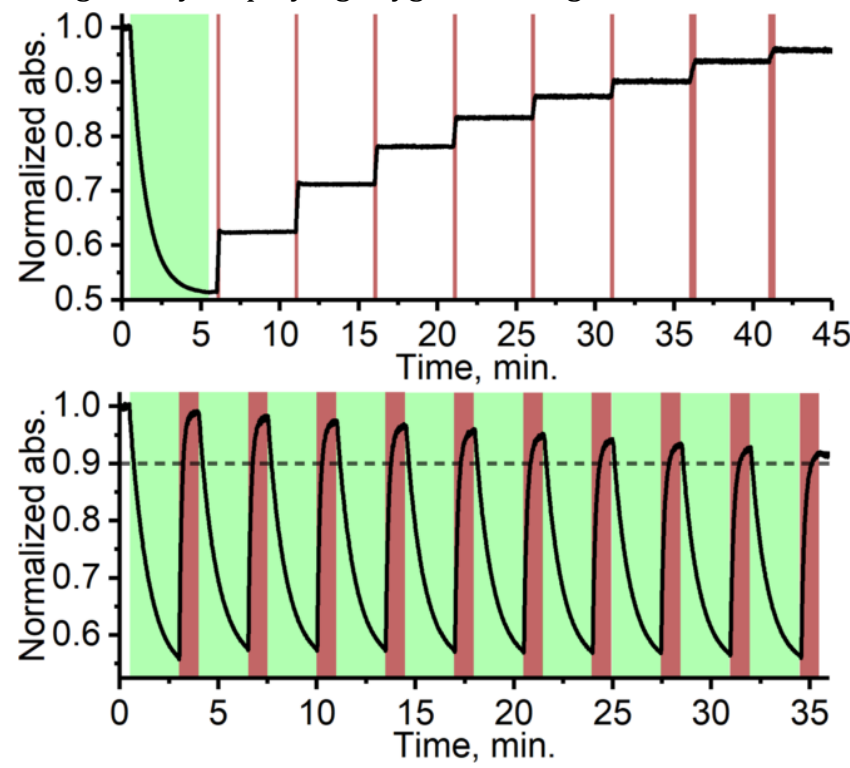

Figure 4. Stepwise photoisomerization (above) of TFA by exciting PdNP with $10 \mathrm{~s}$ (last two were $20 \mathrm{~s}$ ) doses of $740 \mathrm{~nm}$ excitation (dark red bars) in 5 min intervals. Cyclic photoswitching (below) of TFA/PdNP with 10 cycles of alternating $525 \mathrm{~nm}$ (direct excitation of $E$-TFA, green sections) and $740 \mathrm{~nm}$ (excitation of PdNP, dark red sections).

In summary, we have shown that photoisomerization of ortho-functionalized azobenzenes via triplet energy transfer is rapid with near-unity efficiency under red and near-infrared (up to $770 \mathrm{~nm}$ ) excitation. Detailed studies of the kinetics indicate that triplet-sensitized isomerization is largely entropy-driven. Thus, even sensitizers with triplet energies considerably lower than for the azobenzenes used are still capable of effectively sensitizing the isomerization. Combined with the desirable use of red/NIR excitation, precise control of isomer composition, and repeatable cyclic isomerization, we envision that this approach will emerge as a potent tool for low-energy photoswitching in lightresponsive materials.

\section{ASSOCIATED CONTENT}

Supporting Information. Photophysical characterization of the sensitizers, details of the quenching and photoisomerization studies. This material is available free of charge via the Internet at http://pubs.acs.org.

\section{AUTHOR INFORMATION}

\section{Corresponding Author}

Nikita Durandin - Faculty of Engineering and Natural Sciences, Tampere University, FI-33101 Tampere, Finland, email: nikita.durandin@tuni.fi

\section{Authors}

Jussi Isokuortti - Faculty of Engineering and Natural Sciences, Tampere University, FI-33101 Tampere, Finland 
Kim Kuntze - Faculty of Engineering and Natural Sciences, Tampere University, FI-33101 Tampere, Finland

Matti Virkki - Faculty of Engineering and Natural Sciences, Tampere University, FI-33101 Tampere, Finland

Zafar Ahmed - Faculty of Engineering and Natural Sciences, Tampere University, FI-33101 Tampere, Finland

Elina Vuorimaa-Laukkanen - Faculty of Engineering and Natural Sciences, Tampere University, FI-33101 Tampere, Finland

Mikhail A. Filatov - School of Chemical and Pharmaceutical Sciences, Technological University Dublin, City Campus, Kevin Street, Dublin 8, Ireland

Andrey Turshatov - Institute of Microstructure Technology, Karlsruhe Institute of Technology, Hermann-von-HelmholtzPlatz 1, 76344 Eggenstein-Leopoldshofen, Germany

Timo Laaksonen - Faculty of Engineering and Natural Sciences, Tampere University, FI-33101 Tampere, Finland and Drug Research Program, Division of Pharmaceutical Biosciences, Faculty of Pharmacy, University of Helsinki, FI-00014 Helsinki, Finland

Arri Priimägi - Faculty of Engineering and Natural Sciences, Tampere University, FI-33101 Tampere, Finland

\section{ACKNOWLEDGMENT}

The authors gratefully acknowledge financial support by the Academy of Finland (Grant No. 316893) and the European Research Council (ERC Starting Grant Project PHOTOTUNE, Decision number 679646).

\section{REFERENCES}

(1) Goulet-Hanssens, A.; Eisenreich, F.; Hecht, S. Enlightening Materials with Photoswitches. Adv. Mater. 2020, 32 (20), 1905966.

https://doi.org/https://doi.org/10.1002/adma.201905966. Dattler, D; Fuks, G. Heiser, J.; Moulin, E. Perrot, A.; Yao, X. Giuseppone, N. Design of Collective Motions from Synthetic Molecular Switches, Rotors, and Motors. Chem. Rev. 2020, 120 (1), 310-433. ://doi.org/10.1021/acs.chemrev.9b00288.

Hüll, K.; Morstein, J.; Trauner, D. In Vivo Photopharmacology. Chem. Rev. 2018, 118 (21), 10710-10747. https://doi.org/10.1021/acs.chemrev.8b00037.

(4) Beharry, A. A.; Woolley, G. A. Azobenzene Photoswitches for Biomolecules. Chem. Soc. Rev. 2011, 40 (8), $4422-4437$. https://doi.org/10.1039/C1CS15023E.

(5) Bandara, H. M. D.; Burdette, S. C. Photoisomerization in Different Classes of Azobenzene. Chem. Soc. Rev. 2012, 41 (5), 1809-1825. https://doi.org/10.1039/C1CS15179G.

(6) Bléger, D.; Schwarz, J.; Brouwer, A. M.; Hecht, S. OFluoroazobenzenes as Readily Synthesized Photoswitches Offering Nearly Quantitative Two-Way Isomerization with Visible Light. J. Am. Chem. Soc. 2012, 134 (51), 20597-20600. https://doi.org/10.1021/ja310323y.

(7) Konrad, D. B.; Savasci, G.; Allmendinger, L.; Trauner, D.; Ochsenfeld, C.; Ali, A. M. Computational Design and Synthesis of a Deeply Red-Shifted and Bistable Azobenzene. J. Am. Chem. Soc. 2020, 142 (14), 6538-6547. https://doi.org/10.1021/jacs.9b10430.

Hansen, M. J.; Lerch, M. M.; Szymanski, W.; Feringa, B. L. Direct and Versatile Synthesis of Red-Shifted Azobenzenes. Angew. Chemie Int. Ed. 2016, 55 (43), 13514-13518. https://doi.org/https://doi.org/10.1002/anie.201607529. Goulet-Hanssens, A.; Utecht, M.; Mutruc, D.; Titov, E.; Schwarz, J.; Grubert, L.; Bléger, D.; Saalfrank, P.; Hecht, S. Electrocatalytic Z $\rightarrow$ E Isomerization of Azobenzenes. J. Am. Chem. Soc. 2017, 139 (1), 335-341. https://doi.org/10.1021/jacs.6b10822.

(10) Goulet-Hanssens, A.; Rietze, C.; Titov, E.; Abdullahu, L.; Grubert, L.; Saalfrank, P.; Hecht, S. Hole Catalysis as a General Mechanism for Efficient and Wavelength-Independent $\mathrm{Z} \rightarrow \mathrm{E}$ Azobenzene Isomerization. Chem 2018, 4 (7), 1740-1755. https://doi.org/https://doi.org/10.1016/j.chempr.2018.06. 002.

(11) Hallett-Tapley, G. L.; D’Alfonso, C.; Pacioni, N. L.; McTiernan, C. D.; González-Béjar, M.; Lanzalunga, O.; Alarcon, E. I.; Scaiano, J. C. Gold Nanoparticle Catalysis of the Cis-Trans Isomerization of Azobenzene. Chem. Commun. 2013, 49 (86), 10073-10075. https://doi.org/10.1039/C3CC41669K.

(12) Jiang, Z.; Xu, M.; Li, F.; Yu, Y. Red-Light-Controllable LiquidCrystal Soft Actuators via Low-Power Excited Upconversion Based on Triplet-Triplet Annihilation. J. Am. Chem. Soc. 2013, 135 (44), 16446-16453. https://doi.org/10.1021/ja406020r.

(13) Wang, L.; Dong, H.; Li, Y.; Xue, C.; Sun, L.-D.; Yan, C.-H.; Li, Q Reversible Near-Infrared Light Directed Reflection in a SelfOrganized Helical Superstructure Loaded with Upconversion Nanoparticles. J. Am. Chem. Soc. 2014, 136 (12), 4480-4483. https://doi.org/10.1021/ja500933h.

(14) Jones, L. B.; Hammond, G. S. Mechanisms of Photochemical Reactions in Solution. XXX.1 Photosensitized Isomerization of Azobenzene. J. Am. Chem. Soc. 1965, 87 (18), 4219-4220. https://doi.org/10.1021/ja01096a059.

(15) Ronayette, J.; Arnaud, R.; Lebourgeois, P.; Lemaire, J. Isomérisation Photochimique de l'azobenzène En Solution. I. Can. J. Chem. 1974, 52 (10), 1848-1857. https://doi.org/10.1139/v74-264.

(16) Ronayette, J.; Arnaud, R.; Lemaire, J. Isomérisation Photosensibilisée Par Des Colorants et Photoréduction de l'azobenzène En Solution. II. Can. J. Chem. 1974, 52 (10), 1858-1867. https://doi.org/10.1139/v74-265.

(17) Bortolus, P.; Monti, S. Cis-Trans Photoisomerization of Azobenzene. Solvent and Triplet Donors Effects. J. Phys. Chem. 1979, 83 (6), 648-652. https://doi.org/10.1021/j100469a002.

(18) Cembran, A.; Bernardi, F.; Garavelli, M.; Gagliardi, L.; Orlandi, G. On the Mechanism of the Cis-trans Isomerization in the Lowest Electronic States of Azobenzene: S0, S1, and T1. J. Am. Chem. Soc. 2004, 126 (10), 3234-3243. https://doi.org/10.1021/ja038327y.

(19) Bléger, D.; Hecht, S. Visible-Light-Activated Molecular Switches. Angew. Chemie Int. Ed. 2015, 54 (39), 1133811349.

https://doi.org/https://doi.org/10.1002/anie.201500628.

(20) Samanta, S.; Beharry, A. A.; Sadovski, O.; McCormick, T. M.; Babalhavaeji, A.; Tropepe, V.; Woolley, G. A. Photoswitching Azo Compounds in Vivo with Red Light. J. Am. Chem. Soc. 2013, 135 (26), 9777-9784 https://doi.org/10.1021/ja402220t.

(21) Dong, M.; Babalhavaeji, A.; Samanta, S.; Beharry, A. A. Woolley, G. A. Red-Shifting Azobenzene Photoswitches for in Vivo Use. Acc. Chem. Res. 2015, 48 (10), 2662-2670. https://doi.org/10.1021/acs.accounts.5b00270.

(22) Fuchter, M. J. On the Promise of Photopharmacology Using Photoswitches: A Medicinal Chemist's Perspective. J. Med Chem. 2020, 63 (20), 11436-11447. https://doi.org/10.1021/acs.jmedchem.0c00629.

(23) Rogers, J. E.; Nguyen, K. A.; Hufnagle, D. C.; McLean, D. G.; Su, W.; Gossett, K. M.; Burke, A. R.; Vinogradov, S. A.; Pachter, R.; 
Fleitz, P. A. Observation and Interpretation of Annulated Porphyrins: Studies on the Photophysical Properties of MesoTetraphenylmetalloporphyrins. J. Phys. Chem. A 2003, 107 (51), 11331-11339. https://doi.org/10.1021/jp0354705.

(24) Rozhkov, V. V; Khajehpour, M.; Vinogradov, S. A. Luminescent Zn and Pd Tetranaphthaloporphyrins. Inorg. Chem. 2003, 42 (14), 4253-4255. https://doi.org/10.1021/ic034257k.

(25) Finikova, O. S.; Aleshchenkov, S. E.; Briñas, R. P.; Cheprakov, A. V; Carroll, P. J.; Vinogradov, S. A. Synthesis of Symmetrical Tetraaryltetranaphtho[2,3] Porphyrins. J. Org. Chem. 2005, 70 (12), 4617-4628. https://doi.org/10.1021/jo047741t.

(26) Knie, C.; Utecht, M.; Zhao, F.; Kulla, H.; Kovalenko, S.; Brouwer, A. M.; Saalfrank, P.; Hecht, S.; Bléger, D. OrthoFluoroazobenzenes: Visible Light Switches with Very LongLived Z Isomers. Chem. - A Eur. J. 2014, 20 (50), 1649216501.

https://doi.org/https://doi.org/10.1002/chem.201404649.

(27) Ahmed, Z.; Siiskonen, A.; Virkki, M.; Priimagi, A. Controlling Azobenzene Photoswitching through Combined OrthoFluorination and -Amination. Chem. Commun. 2017, 53 (93), 12520-12523. https://doi.org/10.1039/C7CC07308A.

(28) Dzebo, D.; Moth-Poulsen, K.; Albinsson, B. Robust TripletTriplet Annihilation Photon Upconversion by Efficient Oxygen Scavenging. Photochem. Photobiol. Sci. 2017, 16 (8), 1327-1334. https://doi.org/10.1039/C7PP00201G.

(29) Sandros, K. Transfer of Triplet State Energy in Fluid Solutions. III. Reversible Energy Transfer. Acta Chim. Scand. 1964, 18, 2355-2374. https://doi.org/10.3891/acta.chem.scand.18-
2355.

(30) Nakamura, A.; Doi, K.; Tatsumi, K.; Otsuka, S. Catalysis by LowValent Diamagnetic Transition-Metal Complexes of the CisTrans Isomerization of Azobenzenes. J. Mol. Catal. 1976, 1 (6), 417-429. https://doi.org/https://doi.org/10.1016/03045102(76)85003-1.

(31) Ciccone, S.; Halpern, J. Catalysis of the Cis-Trans Isomerization of Azobenzene by Acids and Cupric Salts. Can. J. Chem. 1959, 37 (11), 1903-1910. https://doi.org/10.1139/v59-278.

(32) Gagliardi, L.; Orlandi, G.; Bernardi, F.; Cembran, A.; Garavelli, M. A Theoretical Study of the Lowest Electronic States of Azobenzene: The Role of Torsion Coordinate in the Cis-Trans Photoisomerization. Theor. Chem. Acc. 2004, 111 (2), 363372. https://doi.org/10.1007/s00214-003-0528-1.

(33) Cheng, Y. Y.; Fückel, B.; Khoury, T.; Clady, R. G. C. R.; EkinsDaukes, N. J.; Crossley, M. J.; Schmidt, T. W. Entropically Driven Photochemical Upconversion. J. Phys. Chem. A 2011, 115 (6), 1047-1053. https://doi.org/10.1021/jp108839g.

(34) Isokuortti, J.; Allu, S. R.; Efimov, A.; Vuorimaa-Laukkanen, E.; Tkachenko, N. V; Vinogradov, S. A.; Laaksonen, T.; Durandin, N. A. Endothermic and Exothermic Energy Transfer Made Equally Efficient for Triplet-Triplet Annihilation Upconversion. J. Phys. Chem. Lett. 2020, 11 (1), 318-324. https://doi.org/10.1021/acs.jpclett.9b03466.

\section{Table of Contents artwork}

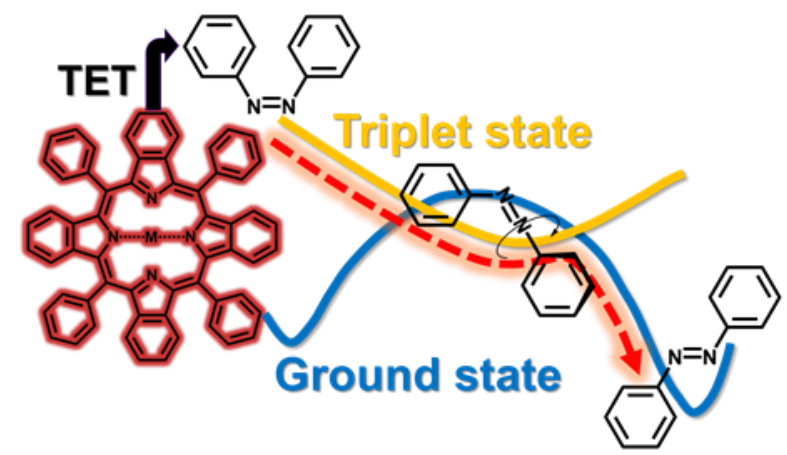

